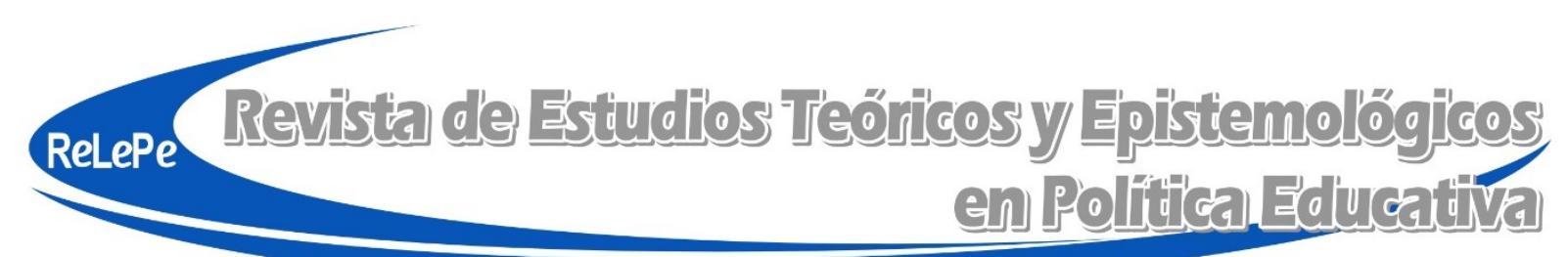

ISSN 2409-3696

doi) https://doi.org/10.5212/retepe.v.5.14425.003

\title{
Redes, experts e a internacionalização de políticas educacionais
}

\section{Networks, experts and the internationalization of education policies}

\section{Redes, expertos y la internacionalización de políticas educativas}

\author{
Eneida Oto Shiroma* \\ http://orcid.org/0000-0002-0506-7058
}

\begin{abstract}
Resumo: Este artigo discute a relevância das redes de políticas públicas regionais para os estudos sobre o alinhamento das agendas internacionais e locais. $\mathrm{O}$ isomorfismo das reformas adotadas em diferentes países leva a estudar o fenômeno do "empréstimo" de políticas. Pesquisa-se uma rede de especialistas convidados pela Unesco para desenvolver um projeto regional de políticas docentes para a América Latina. Analisamse seus membros, filiações institucionais, documentos e propostas. Mapeia-se a participação anterior de especialistas em organizações internacionais, cargos no Estado, em universidades e suas ações conjuntas. A etnografia da rede permitiu apontar a permeabilidade público-privada. Esta abordagem destacou que especialistas engajados em redes regionais disseminam suas ideias, promovem a circulação internacional de políticas e contribuem para a construção da recepção ativa de suas recomendações em nível local. $\mathrm{O}$ mapeamento de redes se mostrou um recurso metodológico fecundo para investigar o complexo processo de formulação de políticas e o papel dos experts no estabelecimento de agendas para a Educação.

Palavras-chave: Redes de políticas públicas. Transferência de política. Especialistas.
\end{abstract}

Abstract: This paper discusses the regional policy networks relevance for studies about the international local agendas alignment. The reform isomorphism adopted in different countries led us to research the borrowing policies phenomenon. We investigated an experts network invited by Unesco to develop a regional project on teaching policies for the Latin America. We analyzed their members, institutional filiations, documents and proposals. We mapped the previous expert participation in international organizations, political charge in State, universities and their joint actions. The network ethnography allowed us to point out the public-private permeability. Our approach highlighted that experts, engaged in regional networks disseminate their ideas, promote a policies international circulation and contribute for building the active reception of their recommendations at a local level. Mapping networks proves to be a fruitful methodological resource to investigate the policymaking complex process and experts role on establishing the Education agenda.

Keywords: Public policies networks. Policy transfer. Experts.

Resumen: Este artículo discute la relevancia de las redes de políticas públicas regionales para estudiar el alineamiento de las agendas internacionales y locales. El isomorfismo de las reformas adoptadas en diferentes países nos llevó a investigar el fenómeno de "préstamo" de políticas. Investigamos una red de expertos invitados por la Unesco para desarrollar un proyecto regional sobre políticas docentes para América Latina. Analizamos sus miembros, filiaciones institucionales, documentos y propuestas. Mapeamos la

\footnotetext{
* Professora da Universidade Federal de Santa Catarina. Doutora em Educação pela Universidade Estadual de Campinas. Bolsista de Produtividade em Pesquisa - CNPq. E-mail: <eneida.shiroma@ufsc.br>.
} 
participación previa de los expertos en organizaciones internacionales, cargos en el Estado, universidades y sus acciones conjuntas. La etnografía de la red nos permitió apuntar la permeabilidad público-privada. Este abordaje resaltó que expertos comprometidos en redes regionales diseminan sus ideas, promueven la circulación internacional de políticas y contribuyen para construcción de la recepción activa de sus recomendaciones a nivel local. El mapeo de redes se ha mostrado como un recurso metodológico fecundo para investigar el complejo proceso de formulación de políticas y el rol de los expertos en establecer la agenda para la Educación.

Palabras clave: Redes de políticas públicas. Transferencia de política. Expertos.

\section{Introdução}

Discursos sobre qualidade da educação circulam pelo globo difundindo formas padronizadas de pensar problemas e soluções. Este processo é referido por alguns autores como policy transfer. Cowen (2006) o define como um movimento de ideias, políticas e práticas de educação de um local para outro, normalmente, entre fronteiras nacionais. Por vezes, tal fenômeno decorre de programas de cooperação multilateral estabelecidos entre Governos. Segundo Steiner-Khamsi e Waldow (2012), a metáfora da migração de reformas [travelling reforms] evoca a ideia de globalização. Nesse espaço de circulação de conhecimento potencializado pela internet, mídia e redes sociais, eventos políticos e científicos, as ideias têm portadores de diferentes calibres que, conforme seus interesses, patrocinam e aceleram sua difusão.

A crescente participação de organizações multilaterais na formulação de políticas nacionais provoca a reflexão sobre seu papel indutor de reformas. Além de fornecerem aporte financeiro, o fenômeno do empréstimo de políticas [borrowing/lending policies] abrange assessorias para implantação, mensuração, plataforma tecnológica, dados e informações estatísticas, serviços de comparações, criação de rankings, entre outros, por meio dos quais essas agências tentam mostrar sua expertise em reformas se constituindo em importantes atores na governança transnacional da Educação.

Neste artigo, discute-se o papel das redes de políticas públicas na difusão de ideias como forma de explicar o isomorfismo das reformas e os processos de alinhamento de agendas. As análises aqui apresentadas resultam de uma pesquisa qualitativa em que foram investigadas propostas internacionais para a Educação e as formas de disseminá-las no Continente (SHIROMA et al., 2016).

Elegeu-se para estudo de caso uma rede de experts convidados pela Unesco para elaborar o Proyecto Estratégico Regional sobre Docentes para a América Latina y el Caribe (Perdalc). Estudou-se a composição identificando as trajetórias de seus membros, pesquisando as filiações institucionais, analisando os documentos que produziram e as estratégias usadas para transformá-las em políticas públicas no Brasil. Buscando conhecer as articulações entre interesses políticos e econômicos foram mapeadas as participações anteriores dos experts em projetos internacionais, cargos no Estado, think tanks, universidades e ações conjuntas que realizaram. Os documentos foram obtidos na internet e na visita realizada ao Centro de Estudos de Políticas e Práticas em Educação (UNESCO, 2014), em Santiago do Chile, no qual também foram realizadas entrevistas com os coordenadores do projeto. Investigaram-se as ações que a rede usa para difundir suas recomendações nos países da região, de modo a influenciar os legisladores e tomadores de decisão em nível nacional. Por meio da análise de redes sociais se procura dar visibilidade à articulação dos principais atores do Perdalc com outras redes nacionais, que formulam a política educacional brasileira. 
Estudar o processo de atuação de redes envolvendo consultores de organizações multilaterais, universidade, Estado e organizações da sociedade civil para compreender como as redes interferem na forma de fazer políticas educacionais demandou esforços de construção teórica e propiciou avanços metodológicos. Tendo o materialismo histórico como referencial teóricometodológico se utilizou a abordagem de redes políticas como ferramenta analítica para pesquisar as relações global-nacional-local no complexo processo de formulação de políticas públicas. A etnografia de redes possibilitou compilar informações e construir os sociogramas, que descrevem as relações mapeadas entre os sujeitos e organizações, fornecendo elementos para se compreender a elaboração da hegemonia discursiva em Educação.

Este artigo está composto de quatro partes. Na primeira se discute a relevância das organizações multilaterais na formulação de agendas e seus mecanismos de transferência de políticas, das formas mais impositivas até as soft transfer. A segunda parte trata do papel dos especialistas na produção e na circulação de conhecimento sobre políticas e o papel estratégico das redes em sua difusão. $\mathrm{Na}$ terceira é apresentada a rede de experts criada pela Unesco para propor políticas docentes e as formas de disseminá-las na América Latina e Caribe. Por fim, discute-se a contribuição dos estudos sobre redes para as pesquisas sobre políticas educacionais.

\section{Organizações Multilaterais e a indução de políticas educacionais}

Pesquisador dos efeitos da globalização nas políticas educacionais, Roger Dale publicou, em 1999, um artigo seminal intitulado: "Specifying globalization effects on national policy: a focus on the mechanisms", no qual indagava como as políticas eram formadas, moldadas e dirigidas? Quais as consequências da globalização e como afetavam as políticas educacionais e os processos de formulação de políticas? Em sua interpretação, as forças que pressionam a modernização das economias nacionais impelem, também, a adaptação de seus sistemas, instituições e legislação à competição internacional. Alertava o autor que o isomorfismo das políticas educacionais estava relacionado à globalização, porém seria equivocado reduzi-lo à ideia simplificada de imposição de medidas idênticas a todos os países, uma vez que a globalização não é um processo homogêneo e nem visa produzir resultados iguais nas nações. Dale (2007) ${ }^{1}$ esclarece que imposição designa um processo de natureza compulsória, com forte pressão exercida externamente pelo estabelecimento de metas, como ocorre, por exemplo, com as condicionalidades que acompanham os empréstimos do Banco Mundial. Existem, contudo, outros meios usados pelas organizações multilaterais para influenciar as reformas educacionais.

As propostas dessas agências se orientam por um conjunto de medidas para responder às crises do capital e aos problemas pautados pelos países hegemônicos que indicam a direção para a qual as políticas dos diferentes Estados nacionais precisariam ser orientadas para assegurar o processo de acumulação, em qualquer parte do globo, considerando-se a crescente financeirização da economia. Contrapondo-se à perspectiva monolítica da imposição top-down, Dale (2007) apresenta um leque de mecanismos adotados para explicar a transferência de políticas entre países: empréstimo, aprendizagem, harmonização, disseminação, estandardização, interdependência e imposição.

\footnotetext{
${ }^{1}$ Artigo originalmente publicado no Journal of Education Policy (DALE, 1999) e reeditado, em forma de capítulo, na coletânea The Routledge Falmer Reader in Education Policy and Politics organizada por Bob Lingard e Jenny Ozga, em 2007.
} 
Figura 1 - Uma tipologia de mecanismos de efeitos externos sobre políticas nacionais

\begin{tabular}{|c|c|c|c|c|c|c|c|c|}
\hline \multirow{3}{*}{$\begin{array}{l}\text { CHARACTERISTICS } \\
\text { OF EFFECT } \\
\text { MECHANISMS }\end{array}$} & \multicolumn{8}{|c|}{ MECHANISMS OF EXTERNAL EFFECTS } \\
\hline & \multirow[t]{2}{*}{ BORROWING } & \multicolumn{2}{|c|}{ LEARNING } & \multirow{2}{*}{$\begin{array}{l}\text { HARMON- } \\
\text { ISATION }\end{array}$} & \multirow{2}{*}{$\begin{array}{l}\text { DISSEMIN- } \\
\text { ATION }\end{array}$} & \multirow{2}{*}{$\begin{array}{l}\text { STANDARD- } \\
\text { ISATION }\end{array}$} & \multirow{2}{*}{$\begin{array}{c}\text { INSTALLING } \\
\text { INTERDEPEN- } \\
\text { DENCE }\end{array}$} & \multirow[t]{2}{*}{ IMPOSITION } \\
\hline & & "NORMAL" & 'PARADGGMATIC' & & & & & \\
\hline $\begin{array}{l}\text { NATURE OF } \\
\text { RELATIONSHIP }\end{array}$ & \begin{tabular}{|l} 
VOLUNTARY \\
\end{tabular} & VOLUNTARY & \begin{tabular}{|l} 
FORMALLY \\
VOLUNTARY \\
\end{tabular} & \begin{tabular}{|l} 
FORMALLY \\
VOLUNTARY \\
\end{tabular} & $\begin{array}{l}\text { FORMALLY } \\
\text { VOLUNTARY } \\
\end{array}$ & \begin{tabular}{|l|} 
FORMALLY \\
VOLUNTARY \\
\end{tabular} & VOLUNTARY & COMPULSORY \\
\hline $\begin{array}{l}\text { EXPLICITNESS OF } \\
\text { PROCESS }\end{array}$ & EXPLICIT & VARIES & VARIES & EXPLICIT & EXPLICIT & QUITE IMPLICIT & EXPLICIT & EXPLICIT \\
\hline SCOPE & $\begin{array}{l}\text { PARTICULAR } \\
\text { POLICY PROCESS }\end{array}$ & $\begin{array}{l}\text { RECOGNISED } \\
\text { PARAMETERS } \\
\text { POLICY } \\
\text { PROCESS } \\
\end{array}$ & \begin{tabular}{|l|} 
POLICY \\
PROCESS AND \\
POLICY GOALS
\end{tabular} & $\begin{array}{l}\text { MULTIPLE } \\
\text { POLICIES }\end{array}$ & $\begin{array}{l}\text { MULTIPLE } \\
\text { POLICIES }\end{array}$ & $\begin{array}{l}\text { MULTIPLE } \\
\text { POLICIES }\end{array}$ & POLICY GOALS & $\begin{array}{l}\text { PARTICULAR } \\
\text { POLICY GOALS }\end{array}$ \\
\hline $\begin{array}{l}\text { LOCUS OF } \\
\text { VIABILITY }\end{array}$ & NATIONAL & NATIONAL & EXTERNAL & $\begin{array}{l}\text { REGIONAL } \\
\text { ORGANIS- } \\
\text { ATION }\end{array}$ & $\begin{array}{l}\text { EXTERNAL/ } \\
\text { NATIONAL }\end{array}$ & \begin{tabular}{|l} 
INTERNAT- \\
IONAL FORA
\end{tabular} & $\begin{array}{l}\text { COMMON } \\
\text { HERITAGE OF } \\
\text { HUMANKIND }\end{array}$ & $\begin{array}{l}\text { INTERNAT- } \\
\text { IONAL } \\
\text { ORGANIS- } \\
\text { ATION } \\
\end{array}$ \\
\hline PROCESS & $\begin{array}{l}\text { BORROWING/ } \\
\text { IMITATION }\end{array}$ & 'LEARNING' & 'TEACHING' & $\begin{array}{l}\text { COLLECTIVE } \\
\text { AGREEMENT }\end{array}$ & $\begin{array}{l}\text { PERSUASION/ } \\
\text { AGENDA } \\
\text { SETTING }\end{array}$ & $\begin{array}{l}\text { CONDITION OF } \\
\text { MEMBERSHIP }\end{array}$ & PERSUASION & LEVERAGE \\
\hline PARTIES INVOLVED & BILATERAL & $\begin{array}{l}\text { BILATERAL/ } \\
\text { INTERNAT- } \\
\text { IONAL } \\
\end{array}$ & $\begin{array}{l}\text { INTERNAT- } \\
\text { IONAL }\end{array}$ & $\begin{array}{l}\text { MUL.TI- } \\
\text { NATIONAL }\end{array}$ & $\begin{array}{l}\text { INTERNAT- } \\
\text { IONAL }\end{array}$ & \begin{tabular}{|l} 
MULTI- \\
NATIONAL
\end{tabular} & $\begin{array}{l}\text { GLOBAL - } \\
\text { 'BOTTOM UP' }\end{array}$ & $\begin{array}{l}\text { MULT- } \\
\text { INATIONAL }\end{array}$ \\
\hline $\begin{array}{l}\text { SOURCE OF } \\
\text { INITIATION }\end{array}$ & RECIPIENT & $\begin{array}{l}\text { NATIONAL } \\
\text { 'POLICY } \\
\text { COMMUNITY' } \\
\end{array}$ & \begin{tabular}{|l} 
INTERNAT- \\
IONAL MODEL
\end{tabular} & $\begin{array}{l}\text { COLLECTIVELY } \\
\text { BY MEMBERS }\end{array}$ & $\begin{array}{l}\text { SUPRA- } \\
\text { NATIONAL } \\
\text { BODY } \\
\end{array}$ & $\begin{array}{l}\text { 'INTERNAT- } \\
\text { IONAL } \\
\text { COMMUNITY' } \\
\end{array}$ & $\begin{array}{l}\text { NGOs ('GLOBAL } \\
\text { CIVIL SOCIETY') }\end{array}$ & $\begin{array}{l}\text { SUPRA- } \\
\text { NATIONAL } \\
\text { BODY } \\
\end{array}$ \\
\hline $\begin{array}{l}\text { DIMENSION OF } \\
\text { POWER }\end{array}$ & $\begin{array}{l}\text { CONSCIOUS } \\
\text { DECISION }\end{array}$ & $\begin{array}{l}\text { CONSCIOUS } \\
\text { DECISION }\end{array}$ & \begin{tabular}{|l|} 
AGENDA \\
SETTING/ \\
RULES OF \\
GAME \\
\end{tabular} & $\begin{array}{l}\text { CONSCIOUS } \\
\text { DECISION }\end{array}$ & $\begin{array}{l}\text { AGENDA } \\
\text { SETTING }\end{array}$ & $\begin{array}{l}\text { RULES OF } \\
\text { GAME }\end{array}$ & $\begin{array}{l}\text { AGENDA } \\
\text { SETTING }\end{array}$ & $\begin{array}{l}\text { ALL THREE } \\
\text { DIMENSIONS }\end{array}$ \\
\hline $\begin{array}{l}\text { NATURE OF EFFECT } \\
\text { ON EDUCATION }\end{array}$ & \begin{tabular}{|l|} 
DIRECT (ON \\
SECTOR OR \\
ORGANISATION)
\end{tabular} & VARIES & VARIES & $\begin{array}{l}\text { IMPLIED - } \\
\text { REGIME AND } \\
\text { SECTOR }\end{array}$ & $\begin{array}{l}\text { DIRECT - } \\
\text { SECTOR }\end{array}$ & $\begin{array}{l}\text { DIRECT - } \\
\text { REGIME - } \\
\text { SECTOR } \\
\text { RELATION } \\
\end{array}$ & $\begin{array}{l}\text { INDIRECT - } \\
\text { REGIME } \\
\text { DIRECT - ORG. }\end{array}$ & $\begin{array}{l}\text { INDIRECT - } \\
\text { REGIME }\end{array}$ \\
\hline $\begin{array}{l}\text { EXAMPLE } \\
\text { FROM } \\
\text { EDUCATION }\end{array}$ & $\begin{array}{l}\text { SCOTVEC IN NEW } \\
\text { ZEALAND }\end{array}$ & $\begin{array}{l}\text { HUMAN } \\
\text { CAPITAL } \\
\text { THEORY IN } \\
1960 \text { S }\end{array}$ & \begin{tabular}{|l|} 
INCREASING \\
USER CHARGES \\
FOR \\
EDUCATION
\end{tabular} & $\begin{array}{l}\text { MAASTRICHT } \\
\text { TREATY }\end{array}$ & $\begin{array}{l}\text { OECD/CERI } \\
\text { ACTIVTY (SEE } \\
\text { PAPADOPOULOS, } \\
\text { 1992) }\end{array}$ & \begin{tabular}{|l|} 
UNESCO \\
SCIENCE \\
POLICY \\
UN DECLAR- \\
ATION ON \\
HUMAN RIGHTS \\
\end{tabular} & $\begin{array}{l}\text { 'GREEN' } \\
\text { CURRICULUM } \\
\text { MATERIALS }\end{array}$ & $\begin{array}{l}\text { WORLD BANK } \\
\text { EDUCATION } \\
\text { LOANS }\end{array}$ \\
\hline
\end{tabular}

Fonte: Dale (1999, p. 6).

O autor analisa várias dimensões desse processo: natureza da relação; explicitação do processo; escopo; lócus; processo de introdução; atores envolvidos; fonte que dá início ao processo de transferência; relações de poder e natureza do efeito sobre a Educação. Para compreender se as políticas são inspiradas, induzidas ou adaptadas é fundamental analisar a natureza da relação entre os países; conhecer o processo histórico e a relação entre seus principais atores na formulação da política.

Perry e Tor (2007) observam que a transferência de ideias e de políticas educacionais ocorre em um contínuo de poder entre forças internas e externas. Denominam "difusão" o processo de soft transfer que ocorre por forças menos visíveis. Já a imposição se refere a um processo de indução externa, como nos casos de ocupação militar ou colonização. Os receptores podem não desejar o conteúdo da transferência, mas se sentem obrigados a aceitar para que possam receber outros benefícios. Os que impõem não se preocupam em obter aprovação dos receptores. É um processo abertamente autoritário, sem ocultação. Segundo os autores, a aprendizagem tem várias nuances, pode derivar de transferência contingencial ou a informada, inspirada na experiência do outro, ou uma adaptação dessa, um híbrido entre essa e o existente, uma síntese. 
Figura 2 - Formas de Transferência Educacional

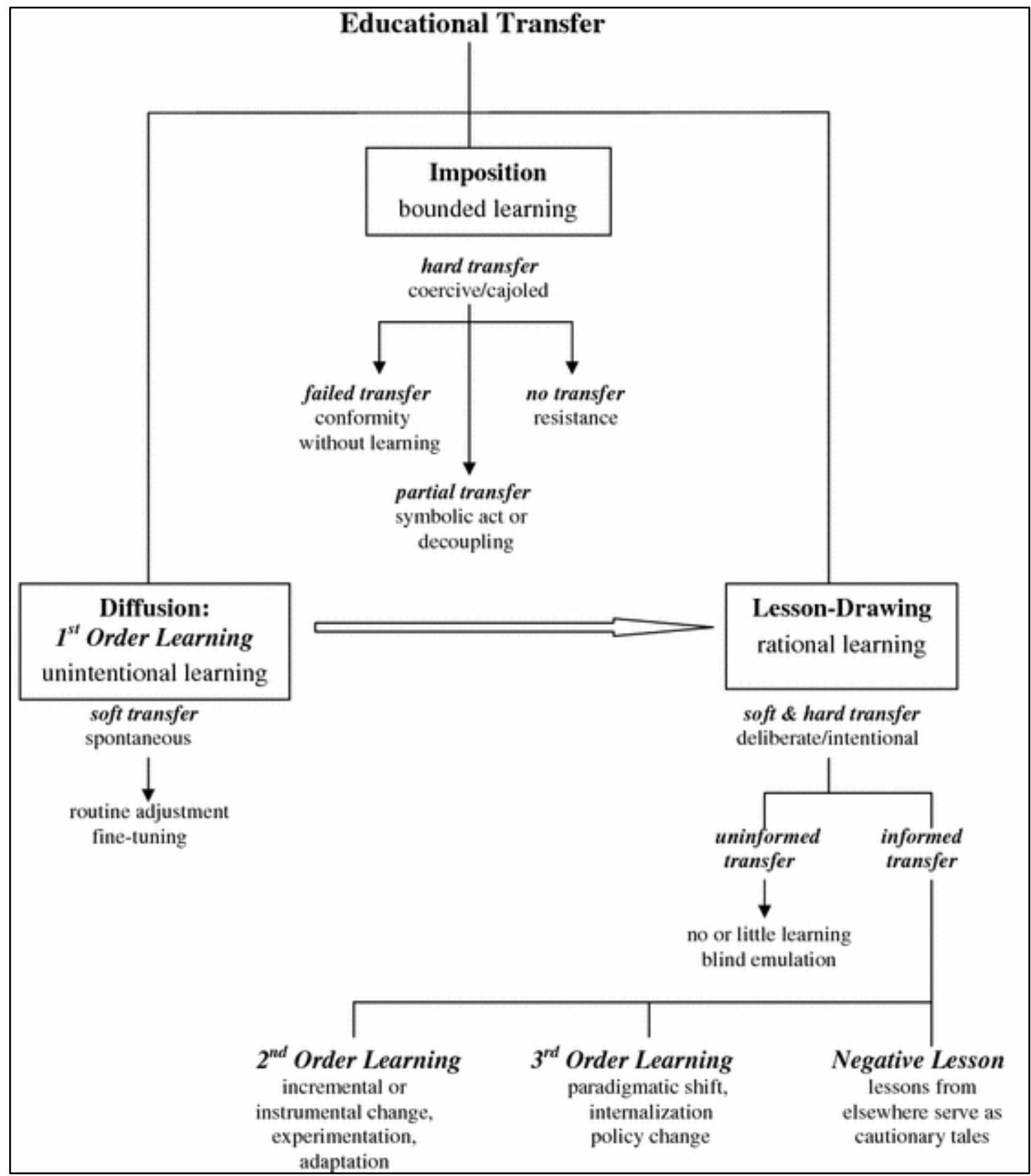

Fonte: Perry e Tor (2008, p. 518).

Esses modelos de transferência de política levam a problematizar que, no espaço político supranacional, não fica claro quem tem a autoridade para definir as regulamentações, quem faz as regras e quem tem que se submeter a essas. Compreender os processos de construção de políticas transnacionais requer investigar, além das proposições das Organizações Multilaterais, a ação das redes de políticas públicas que possuem ramificações em vários Continentes e atua no campo educacional procurando compreender quem são e como atuam os agentes da transferência.

Para conhecer os processos de difusão de ideias efetuados pelas redes, pesquisa-se o papel dos especialistas na produção e circulação do conhecimento para a política. Considera-se que documentos, relatórios, textos e discursos por eles produzidos ou adaptados cumprem um papel fundamental de soft transfer, na medida em que difundem dados e interpretações, apresentados como 
evidência para embasar as propostas e "contagiar" os formuladores de políticas, gestores e conquistar novas audiências. Buscando conhecer como atuam os agentes da transferência se fez uma revisão da literatura sobre experts e redes de governança.

\section{Papel dos experts nas Redes de Políticas Públicas}

Redes de governança reúnem representantes de agências multilaterais, governos nacionais, organizações sociais, think thanks, empreendedores sociais e corporações multinacionais e são apresentadas como alternativa política para as "ineficiências" do Estado. Assim, tais redes operam como estruturas acopladas ao Estado, sinalizando reconfigurações em sua função, passando o Estado a ser visto como coordenador de "ações que reúnem múltiplos atores ao redor de um projeto comum e implantador de políticas públicas em parceria com o setor privado" (ARAÚJO Jr., 2013, p. 64). Considerando que as ações das redes de políticas públicas ultrapassam as fronteiras nacionais, tendem a demandar uma regulação transnacional.

As Organizações Multilaterais se apressaram em demonstrar que dispõem de condições e expertise para assumir este papel representando, em tese, interesses universais. A aparente neutralidade política se reforça com a aparente neutralidade científica das pesquisas que patrocinam a fim de se munirem de evidências para lastrear suas recomendações aos Estados-nação. Nessa empreitada, a OCDE (FAZEKAS; BURNS, 2012) ressalta o papel das instituições de pesquisa na produção de conhecimento mediado por indivíduos e organizações, que circulam entre os formuladores de políticas, profissionais e usuários.

Figura 3 - Conceptual framework for research knowledge mobilisation

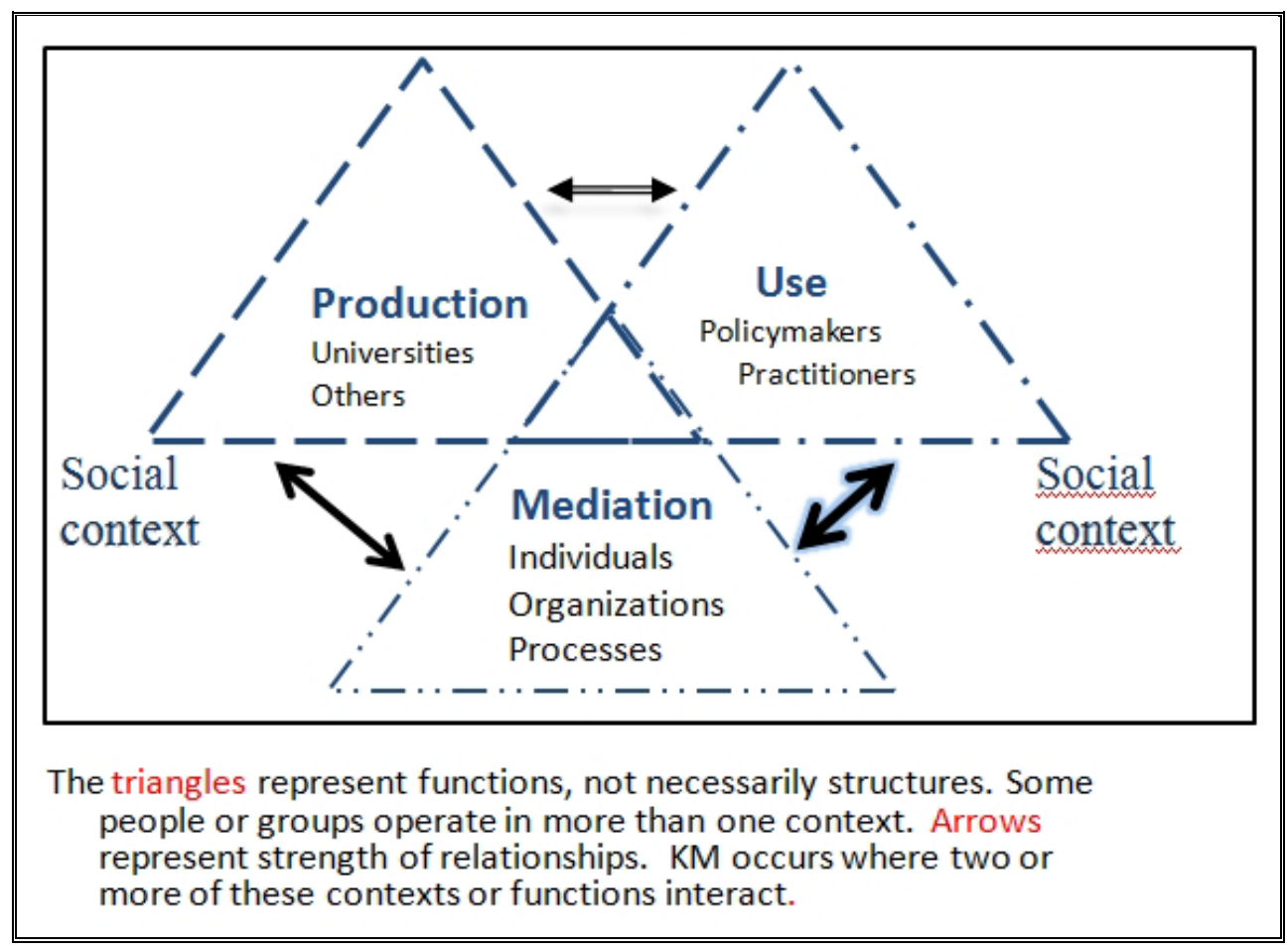

Fonte: Levin (2013, p. 155 apud FAZEKAS; BURNS, 2012, p. 17).

A preocupação com a produção e mobilização de conhecimento para a política põe em relevo a função estratégica das universidades, fundações e institutos de pesquisa para a governança. Experts põem em circulação concepções, valores, modelos, formas de pensar e agir. Associados 
aos gestores assumem, nas redes, a função de ativar pessoas, mobilizar recursos, construir consensos, capacity building (KU; YUEN-TSANG, 2011). Sob forma de "cooperação técnica" se desenvolvem tarefas cruciais de coleta e de organização de dados, produção de indicadores, comparações, diagnósticos e formação de "recursos humanos".

Redes de políticas públicas atuam como intelectuais orgânicos a serviço da expansão da economia de mercado e do engajamento do setor privado na governança da Educação, disseminando a visão de Estado ineficaz, burocrático e, portanto, fadado a fracassar em suas principais atividades. A contratação de especialistas, que já tenham trabalhado juntos e possuam amplo leque de relações com universidades, editoras, agências internacionais, experiência em cargos públicos e com formação de formadores é um aspecto crucial para a internacionalização de políticas educacionais, tanto porque a produção de evidências para as políticas é crucial para sua aceitação pela sociedade, quanto pela constituição de clusters, relações de sujeitos com grande proximidade em uma rede, que é um pré-requisito para qualquer implementação de reformas (HANNEMAN; RIDDLE, 2005). Assim, os experts portadores da legitimação dada pelo conhecimento especializado são agentes estratégicos nas redes de políticas públicas.

\section{Experts: produzindo evidências e legitimidade para as políticas}

A disseminação de novas ideias esbarra nos limites postos pelo instituído, demanda reformas aos dispositivos jurídico-normativos, o que não acontece apenas pelos esforços de comunicação do emissor aos receptores. Mais que condições objetivas e requisitos técnicos, a adaptação e a institucionalização de novas políticas demandam conhecimento do funcionamento da máquina estatal, know-how e know-who e, por mais que as organizações multilaterais trabalhem com envio de consultores para as diversas regiões do globo, as reformas para impactar a governança demandam um conhecimento da história e política do país no qual serão implementadas, até mesmo para enfrentar as resistências e educar o consenso (NEVES, 2005). Esse desafio põe em evidência o papel fundamental exercido pelos especialistas de cada país na transferência de ideias que deem sustentação às políticas educacionais. São pesquisadores com vasta experiência tanto na academia quanto na assessoria a agências internacionais, a órgãos públicos e que por estarem inseridos em múltiplas redes se tornam atores estratégicos na transferência de conhecimentos para a política.

O desafio de analisar o papel e a atuação dos experts requer relacionar a origem e os objetivos das redes aos objetivos mais amplos das frações de classe dominantes, e as relações sociais conflituosas características da sociedade de classe em que se vive. Esses intelectuais participam de diversos aparelhos privados de hegemonia e, por vezes, ocupam funções voltadas à esfera jurídicoadministrativa, com vistas à manutenção do grupo social hegemônico. No projeto do capital, atuam como porta-vozes de interessados em reformar a Educação. Criam metas, estabelecem objetivos, com pretensão de liderar a governança de determinado setor. A produção discursiva é relevante para criar clima propício ao acolhimento de propostas internacionais. Nessa empreitada, os experts desempenham um papel estratégico na produção de documentos, de conferências, de publicações, que tentam formar na opinião pública a expectativa de adequar a educação local às supostas demandas da globalização. Textos e discursos podem ser, assim, entendidos como veículos da ideologia, a infraestrutura material necessária à produção e circulação do conhecimento.

A mescla de discursos governamentais e acadêmicos, de órgãos internacionais e nacionais indica que um caminho necessário a ser percorrido pelos pesquisadores é conhecer os processos de "recepção ativa" dos modelos educacionais que circulam pelo mundo. Para isso é importante investigar a "teia de comunicações e veículos organizacionais da circulação de ideias e de pessoas envolvidas no pequeno mundo da fabricação" de políticas (CARVALHO, 2009, p. 159). Além dos 
documentos oficiais, os livros, os periódicos e os eventos científicos constituem outra importante fonte de estudo da circulação e estruturação de um conhecimento educacional de tipo científicopedagógico. Os especialistas promovem eficiente disseminação de novos conceitos, discursos, racionalidade e interpretações, especialmente via redes de profissionais que constituem vias rápidas de transferência de ideias no métier. Com frequência, são convidados a proferir conferências em eventos acadêmicos e empresariais que, não raro, dão origem às publicações e são disponibilizados pela internet multiplicando a audiência. Os experts contratados por organizações multilaterais seguem um script, fornecem o diagnóstico do problema, fazem críticas e ameaças, incutem responsabilidades, reproduzem discursos com previsões atemorizantes e ofertam um leque de soluções para o público incauto sobre o qual exercem influência, gerando ampla confiança em suas recomendações. Juntamente com a mídia tradicional e as redes sociais, difundem ideias e propostas para reformas. No próximo tópico se apresenta uma rede de experts formada a convite da Unesco, buscando entender como produzem consensos e agendas para a Educação.

\section{Rede de experts em políticas docentes}

Prioridades e metas para a educação traçadas em eventos e projetos mundiais como a Conferência Mundial de Educação para Todos (EpT) balizam a elaboração das políticas nacionais. A Unesco, encarregada de liderar o programa EpT, exerce a função de catalisar a formação de parcerias público-privadas nos vários países visando criar alternativas de financiamento. Durante o Fórum Mundial de Educação, em 2000, passou a coordenar o Projeto Estratégico Regional de Docentes para a América Latina e Caribe (Perdalc) concebido como uma estratégia regional para cumprir o pacto global e reformar a Educação na região no período de 2002 a 2017. Para tanto, a OREALC/UNESCO encomendou ao Ceppe da Pontifícia Universidade Católica do Chile o desenvolvimento do Projeto com a perspectiva de identificar os problemas, produzir orientações para o desenho de políticas docentes a partir de informações obtidas com grupos de discussão nacionais e construir uma rede regional de atores que contribuíssem com visão, categorias e critérios para a renovação do campo de deliberação e formulação das políticas docentes na Região (UNESCO, 2013).

O Perdalc está organizado em quatro áreas temáticas prioritárias: 1) formação inicial docente que abrange as condições para o ingresso no curso de formação de professores, processos formativos, instituições e formadores, avaliação, da entrada no exercício profissional e a indução de professores principiantes; 2) formação contínua para tratar instituições responsáveis pelo desenvolvimento profissional; 3) carreira profissional, condições de trabalho, remuneração, avaliação, incentivos e causas do abandono da profissão docente; 4) construção de políticas docentes, com foco nas prioridades, instituições, capacidades de desenho, monitoramento e avaliação das políticas, participação dos atores sociais e aspectos econômicos.

Antes de discutir o conteúdo de suas propostas serão apresentados o mapeamento da rede da Unesco encarregada de elaborar recomendações para as políticas docentes para o Continente.

\section{A configuração da rede de experts na primeira etapa}

Para conhecer essa rede foram pesquisados seus membros, identificando-se as organizações a que estão vinculados tendo em vista dar visibilidade às articulações institucionais, destacando suas atuações no aparelho de Estado, em organizações multilaterais, universidades e corporações nacionais e internacionais. Foram mapeadas as trajetórias, cargos ocupados e inserções em órgãos governamentais e não-governamentais nacionais e internacionais, educacionais e não-educacionais tentando investigar as possibilidades de intervir na Educação pública. Consultados seus currículos, 
sites das instituições em que atuam para coletar os dados e informações por meio da etnografia para demonstrar, com os sociogramas, as relações entre os principais atores da rede.

A equipe de trabalho do PREDALC foi inicialmente constituída por uma Secretaria Técnica, sediada no CEPPE, que juntamente com a Unesco/Orealc convidou os experts de cinco países - Chile, México, Argentina, Brasil e Uruguai - para elaborar os documentos da primeira etapa do projeto. Iniciou-se o mapeamento pelo diretor do projeto, Cristian Cox, que já atuou como consultor do Banco Mundial, da UNESCO, da OCDE e do BID, foi diretor da Unidade Curricular e Avaliador dos Ministérios de Educação do Chile de 1998 a 2006. Foi professor visitante da Universidade de Stanford, e vice-diretor acadêmico da Pontifícia Universidade do Chile no ano de 2006. No que tange à atuação no Brasil, foi investigador do Instituto Fernando Henrique Cardoso (iFHC) e possui publicações com os outros colaboradores do Perdalc como Simon Schwartzman, Beatrice Avalos e Silvia Ortega. Cox participou de vários eventos no Brasil, como do Seminário Inovação e Qualidade na Formação Inicial de Professores, no Instituto Singularidades em 2011, no qual Denise Vaillant, também, participou como palestrante. Elaborouse um quadro demonstrando os vínculos dos participantes da primeira etapa do projeto com universidades e centros de pesquisa. O sociograma da figura 4 apresenta as filiações institucionais destes pesquisadores, indicados nos cinco quadrados, e suas múltiplas articulações com Universidades, Organizações Multilaterais, participação em projetos, cargos públicos, centros de pesquisa e fundações.

Seguiu-se mapeando as informações sobre cada participante retiradas dos currículos disponíveis em sites de domínio público, identificando suas vinculações institucionais e atuações conjuntas. A especialista chilena, Beatrice Avalos fez publicações e foi consultora do Banco Mundial, Unesco, BID, e atuou no Programa de Promoção da Reforma Educativa na América Latina e Caribe (PREAL). A mexicana Silvia Ortega fez publicações e integrou projetos com a Unesco. No Perdalc, elaborou o documento sobre formação continuada. O argentino Mariano Palamidessi ficou encarregado pela organização de um documento sobre organizações docentes. Coordenou o Curso Regional de Formação e Planejamento de Políticas Educativas do IIPE/UNESCO, do qual Avalos também fez parte. O brasileiro, Simon Schwartzman, foi consultor internacional da OCDE, Banco Mundial, fez projetos com a Unesco, publicações para o PREAL e integrou eventos promovidos pela Fundação Carlos Chagas e Fundação Lemann. A uruguaia Denise Vaillant foi consultora internacional do Banco Mundial, Unesco, OCDE, coordenou um grupo de trabalho na Rede Preal, foi professora da Universidade ORT no Uruguai, da Universidade Alberto Hurtado, na qual Avalos também trabalhou, foi coordenadora acadêmica na Universidade da República, foi investigadora da Fundação Konrad Adenauer no Brasil, assim como Cox, Vaillant também foi consultora do iFHC, foi investigadora da ONU para a Educação e para a Cultura de Santigo, foi membro da Comissão Avaliadora do Programa de Educação implementado pela Fundação Victor Civita em 2005. Participou, em 2008, do Seminário de Secretários Estaduais de Educação, promovido pela Fundação Victor Civita e Conselho Nacional dos Secretários de Educação (Consed). Em 2009, publicou um capítulo sobre profissão docente no livro "Políticas Educacionais e coesão social: uma agenda latinoamericana" organizado por Schwartzman e Cox (2009) e publicado pelo iFHC. 
Figura 4 - Rede de experts da primeira etapa do Perdalc

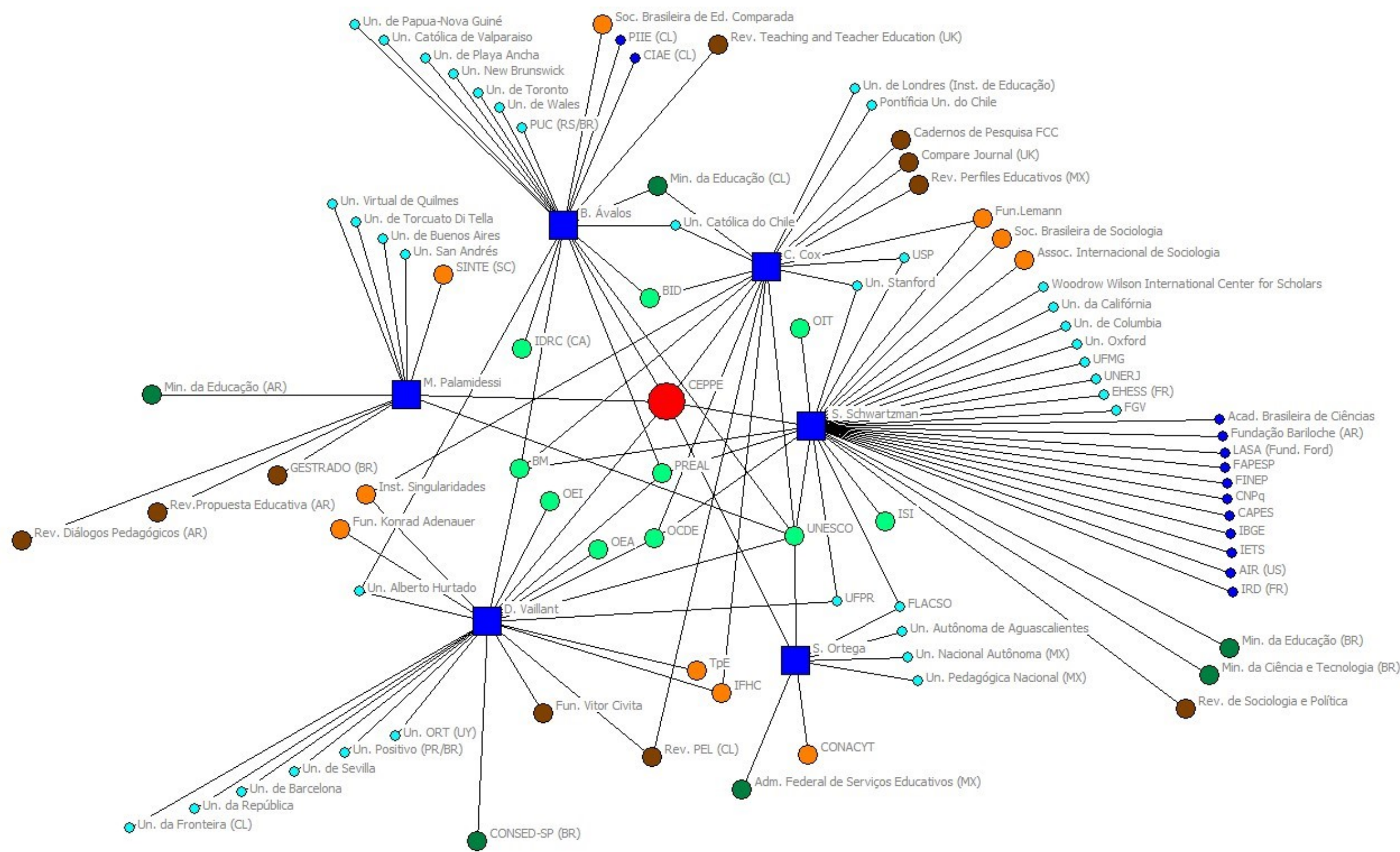

Fonte: Ceppe. Elaboração de Kátia Carvalho Lopes.

Revista de Estudios Teóricos y Epistemológicos en Política Educativa, v. 5, e2014425, p. 1-19, 2020 Disponible en: <https://www.revistas2.uepg.br/index.php/retepe> 


\section{Ampliação da rede na segunda etapa}

$\mathrm{Na}$ segunda fase do Proyecto, os especialistas produziram seis documentos de trabalho e um Cadastro de Experiências Relevantes de Políticas Docentes na América Latina (UNESCO, 2014). Seguiu-se o mesmo procedimento de pesquisa nos sites e currículos para coletar dados sobre os colaboradores da segunda etapa do projeto. Nessa fase, foram incluídos à rede outros membros que também atuaram como consultores do BM, da OCDE, da UNICEF, da OEA, OEI, Preal, do PNUD, do BID, da Organização Pan-americana de Saúde OPS-OMS. Entre os novos integrantes do projeto encontra-se o vice-ministro de Planejamento e Política Econômica da Costa Rica, Ministro da Cultura do Chile, Membro do Conselho Nacional de Educação do Chile, consultores da área de financiamento social, da Secretaria Nacional de Ciência, Tecnologia e Inovação da República do Panamá, e do Conselho Superior de Ciência e Desenvolvimento Tecnológico e do Fundo Nacional de Desenvolvimento Científico e Tecnológico do Chile.

Dessa etapa também participaram o Subsecretário de Educação do Chile, cofundador e diretor do Centro de Estudos de Políticas e Práticas em Educação, Gerente do Centro de Inovação em Educação na Fundação do Chile, membro do comitê diretivo do Centro de Medição MIDEUC do Chile, integrante do "Programa de Mejoramiento de la Calidad y Equidad de la Educación Media del Ministerio de Educación" (MECE-Media) e dirigente do Sistema Nacional de Avaliação de Resultados de Aprendizagem (SIMCE) do Chile. O Projeto contou ainda com a participação da Secretária de Programação e Gestão Educativa do Ministério da Educação e da Cultura na Argentina, de participante do Instituto Internacional de Planejamento da Educação (IIPE/Unesco), do presidente da Sociedade de Investigação Educativa Peruana (SIEP), do diretor de investigações do Instituto de Estudos Peruanos (IEP), e de representante da Secretaria de Educação Pública do México.

Compilando todas essas informações sobre as atuações dos experts das duas etapas do Proyecto se construiu o sociograma (Figura 5) que evidencia as múltiplas relações dos integrantes da rede com Universidades, Institutos e Fundações, Estado e organizações multilaterais. 
Figura 5 - Rede de experts da segunda etapa

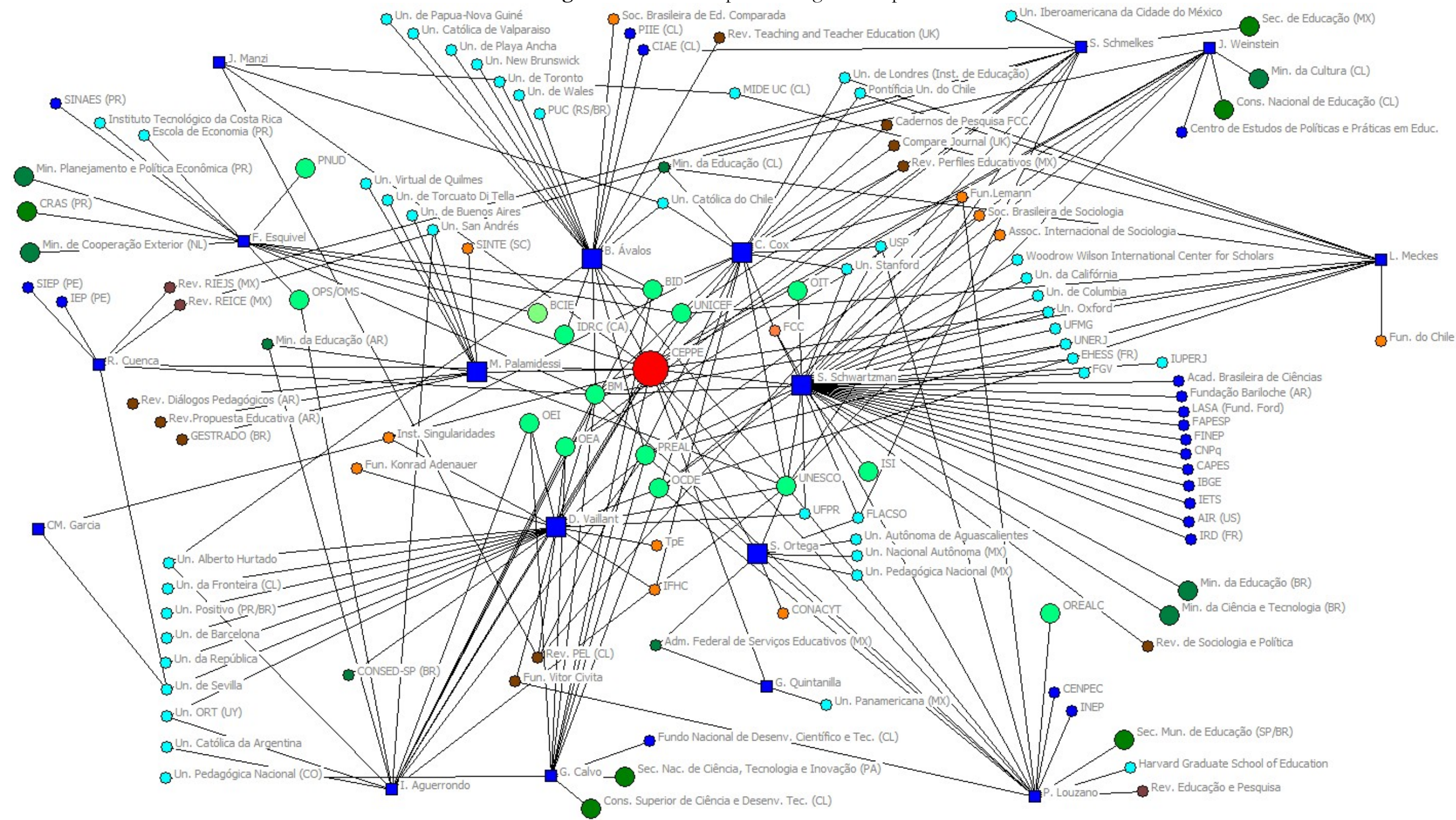

Fonte: UNESCO (2014). Elaboração de Kátia Carvalho Lopes.

Revista de Estudios Teóricos y Epistemológicos en Política Educativa, v. 5, e2014425, p. 1-19, 2020 Disponible en: <https://www.revistas2.uepg.br/index.php/retepe> 
Com base em pesquisas sistemáticas na internet foi identificado que muitos colaboradores contratados na segunda etapa atuaram juntos no aparelho de Estado e possuem trabalhos em coautoria. Essa participação coetânea em Organizações Multilaterais e órgãos governamentais auxilia na compreensão das convergências entre as propostas internacionais de reforma da educação e as agendas locais.

Por meio da entrevista realizada com os membros da Secretaria Técnica do Projeto Regional, soube-se da criação de uma terceira etapa do Perdalc, direcionada à elaboração de políticas públicas para a Educação Infantil. Para esta etapa, a Unesco contratou novos colaboradores que redigiram seis informes nacionais sobre docentes da Educação Infantil em seus respectivos países. A última atividade do projeto ocorreu no Brasil, em 2015, com participação de Ministros da Educação, representantes das Instituições de Ensino, Centros de Investigação e Sindicatos de professores da Educação Infantil de 24 países da região (CUNHA, 2016).

A coordenação do Perdalc coletava informações relevantes sobre problemas e políticas de educação em diversos contextos nacionais contratando pesquisadores de Universidades e Centros de Pesquisa para produzir informes nacionais, estudos e pesquisas sobre suas áreas de expertise. Também, solicitou aos Ministérios de Educação dos países da região, às Instituições acadêmicas e investigadores que preenchessem um formulário fornecendo informações a respeito das experiências exitosas de políticas docentes implantadas em seus países. Essas informações deram origem a um Cadastro de experiências relevantes de políticas docentes (UNESCO, 2014). Outra forma de divulgação das propostas do projeto na região foram os seminários realizados com a presença de três atores fundamentais: acadêmicos, Ministros da Educação e representantes sindicais.

\section{Propostas para políticas docentes na América Latina e Caribe}

O argumento central desenvolvido nos documentos do Perdalc é o da necessidade de docentes em número e preparação compatível às novas demandas e expectativas educacionais considerando a ampliação da diversidade sociocultural dos alunos atendidos, enfraquecimento da instituição familiar e das estruturas comunitárias como esferas de socialização, alargamento temático dos currículos, além da elevação generalizada das metas de aprendizagem (UNESCO, 2013). Supostamente, ao responder a estes requisitos, a Educação estaria contribuindo com a superação da desigualdade e o desenvolvimento de capacidades culturais de base para o crescimento econômico e a cidadania democrática imprescindíveis para o novo milênio. No entanto, advertem os reformadores, que qualquer investida no sistema educativo em prol da qualidade estaria na dependência da qualidade dos professores (UNESCO, 2013). Assim, se colocam à disposição dos Governos da região, munidos de orientações atraentes para a renovação das políticas docentes.

Cônscios da necessidade de formar um novo perfil docente, que atenda às exigências sociais, alardeiam a existência de uma crise generalizada do sistema educacional na região. A finalidade é convencer Governos e sociedade sobre a necessidade urgente de reorientar as políticas docentes para América Latina e Caribe. Iniciam a crítica pela desqualificação dos pretendentes ao magistério antes mesmo de iniciarem os estudos pedagógicos alegando que em função da debilidade dos sistemas escolares, os aspirantes ao magistério não possuem as habilidades essenciais no campo da linguística, matemática e cultura geral que lhes permitam enfrentar as demandas do Ensino Superior, nem obterem resultados satisfatórios como egressos (UNESCO, 2013; 2014). Avaliam que, na formação inicial docente, os estudantes não aprendem de maneira significativa, pois, na visão dos experts, a organização dos programas é inadequada e eivada de fragmentações entre: lógica escolar e lógica acadêmica, dispositivos legais e práticas institucionais, formação 
disciplinar e formação pedagógica, conteúdos gerais e didáticas específicas, tecnologia da comunicação e informação e oportunidades de aprendizagem, gerando uma fenda profunda entre o tipo de formação obtida e os desafios colocados pela prática pedagógica cotidiana (UNESCO, 2013).

Para os especialistas, diversos fatores precarizam a formação contínua dos professores na região como: dificuldades de acesso; descontinuidade; duração limitada; desenhos e processos frequentemente distantes dos interesses e necessidades dos sujeitos e das escolas; precariedade dos formadores; insuficiência de recursos; difícil regulação e articulação das ações de múltiplos agentes e; ausência de uma política clara quanto ao tempo da jornada de trabalho disponível para este fim. Consequentemente, as iniciativas neste âmbito têm sido criticadas por seu baixo impacto na aula e na aprendizagem. A carreira docente, segundo os especialistas do Projeto, não é desenhada a partir das etapas da vida profissional docente, desconsiderando, portanto, os estágios de motivação, de compromisso e de eficácia docente, centrando-se mais nos requisitos de formação e experiência. Isto se reflete no regime de remuneração e compensação, em que se paga igual por diferentes esforços e dedicação dos professores, argumento este usado para sugerirem a institucionalização de novos desenhos de compensação salarial e incentivos, além da avaliação do desempenho docente (UNESCO, 2013). Este conjunto de problemas descritos, de forma cíclica pelos experts, é denunciado como um paradoxo de base: praticamente todo discurso político sobre a docência enfatiza sua importância e centralidade, mas as ações e os desenhos de políticas não exprimem esta suposta posição estratégica. A justificativa apresentada no Projeto é de que as políticas docentes são de alto custo, pouco visíveis para o público, politicamente complexas e de médio e longo prazo para alcançar efeitos esperados.

\section{O plano estratégico da Unesco para os docentes}

As recomendações dos especialistas do Projeto para a superação dos problemas apontados na formação docente na América Latina e Caribe reproduzem as críticas e proposições das agências internacionais. Argumentam que os programas de formação inicial docente padecem de abordagens predominantemente acadêmicas, teóricas e abstratas que distanciam os alunos da realidade escolar (UNESCO, 2013). Em contraposição, propõem medidas "inovadoras" que atentem para a diversidade, com ações formativas vinculadas a realidade das comunidades escolares e as mudanças culturais que, hipoteticamente, impactariam a aprendizagem dos alunos permitindo aos gestores "entregarem" melhores resultados.

A transformação da formação inicial docente, na visão dos experts, não deveria se pautar apenas na seleção de novos conhecimentos, saberes e competências, mas na necessidade de se centrar na prática, isto é, não só devem contar com uma forte formação disciplinar e pedagógica, mas também na conexão destas por meio do "conhecimento pedagógico de conteúdo", o qual "só pode aprender da e na prática". Norteadas por experiências internacionais, as autoras afirmam que os programas exitosos têm em comum uma visão definida do professor que se quer formar em plena coerência com o currículo e enfatizam o trabalho prático na preparação do bom docente (LOUZANO; MORICONI, 2014).

As propostas para a formação continuada indicam a necessidade de reformar as práticas de ensino enfatizando a aprendizagem compartilhada (UNESCO, 2013). A inovação estaria, portanto, em incentivar processos de formação centrados na escola, na qual supostamente se desenvolveria o protagonismo dos coletivos docentes, tendo a prática como fonte de reflexão, de análise e de aprendizagem. Nesta proposta, lidam com o conceito-chave de "aprendizagem profissional colaborativa". Tal possibilidade pode se materializar em várias frentes como a mentoria, o 
coaching, a residência escolar, o incentivo à constituição de "comunidades virtuais de aprendizagem", entre outras.

Em síntese, suas propostas para a formação docente envolvem elevação do nível de exigências para ingresso no magistério, focando na seleção de habilidades como pensamento matemático, resolução de problemas, destrezas e interpretação de texto e motivação para aprender e ensinar; fortalecer os programas de formação docente, os conteúdos curriculares, a avaliação de aprendizagem, e melhorar a qualidade dos formadores com critérios de seleção que assegurem um profissional com experiência docente recente e relevante em estabelecimentos escolares. Para esse efeito, esses estudos recomendam estimular os acadêmicos realizarem pós-graduação de qualidade, nacionais e estrangeiras, oferecer uma formação de qualidade para o trabalho educativo com grupos sociais desfavorecidos e garantir sistemas apropriados de regulação de qualidade dos programas de formação. Ressaltam a necessidade da formação continuada relevante e pertinente, centrada no aprendizado dos estudantes, e associada aos incentivos de progressão na carreira docente, que levem em conta a qualidade do trabalho profissional, as avaliações de desempenho, de modo a construir uma trajetória de desenvolvimento profissional distinguindo as etapas de vida docente.

Segundo Louzano e Moriconi (2014, p.40), "o Estado deve cumprir um papel coordenador dos múltiplos atores, visões e âmbitos institucionais para que se chegue a uma visão comum, contemporânea e válida da docência em cada um dos países". Desse modo, sugerem fortalecer o protagonismo do Estado na construção de acordos sobre o professor a ser formado, indica a real estratégia de dotar o Estado da autoridade necessária para a regulação de toda a trajetória docente. A intenção do Projeto Estratégico é a consecução de um Estado coordenador, regulador e promotor, capaz de dar "coerência sistêmica" aos conhecimentos e competências da docência e possibilitar, consequentemente, a articulação de dois elementos potentes na condução das políticas educacionais, a formulação de standards e o processo de avaliação. Esta junção pretende perpassar toda a estrutura educacional em nome da suposta profissionalização. Todavia, por trás do discurso da profissionalização docente reside o objetivo de regular esta ampla categoria de servidores públicos, os professores, desde a formação, passando pela avaliação, carreira e toda a vida funcional.

$\mathrm{Na}$ ótica dos experts do Projeto, avaliações precisam ter consequências. Referindo-se à avaliação das instituições formadoras, sugerem que as mesmas deverão se comprometer a superar, dentro de um prazo determinado, eventuais debilidades detectadas; aquelas que não cumprirem com os padrões mínimos requeridos para obter seu reconhecimento precisarão ser apoiadas, mas se o resultado deste apoio não surtir melhora, estas deverão fechar ou funcionar junto a outras instituições que estejam certificadas. "De outro modo, se atenta contra a fé pública depositada na instituição e sua função formadora de profissionais sobre a qual descansa, por sua vez, a formação de muitas gerações escolares" (UNESCO, 2013, p.122). Colocando os docentes e as instituições formadoras sob suspeita, tentam justificar a necessidade de auditorias periódicas (SHIROMA; BRITO NETO, 2015, p.17).

Os reformadores argumentam que a criação de sistemas de avaliação dos futuros docentes pode constituir um importante aporte para que as instituições formadoras possam revisar seus currículos e suas práticas em função dos resultados obtidos por seus egressos, assim como devem assumir responsabilidade pelo fracasso dos estudantes, que não adquiram as aprendizagens necessárias. A tese de que a má qualidade do ensino decorre da má qualidade do professor coloca os docentes e as instituições formadoras como inimigos da Pátria, a serem profissionalizados, reformados, combatidos ou substituídos (SHIROMA; BRITO NETO, 2015, p.18). Por fim, para desenvolver políticas docentes com maior efetividade, recomendam a adoção de uma abordagem sistêmica, que concilie critérios de continuidade e mudança, promova a participação dos atores 
Redes, experts e a internacionalização de políticas educacionais

não-governamentais na formulação e institucionalização de políticas docentes. Essa ação não ocorre isolada ou espontaneamente, mas coordenada, como se verá no próximo tópico.

\section{Contribuições da Análise de Redes Sociais para os estudos de políticas educacionais}

A crescente influência de organizações multilaterais que orbitam o aparelho de Estado tem modificado sua configuração. Incrementou-se, notadamente, a participação de organizações da sociedade civil que integram redes sociais internacionais, regionais e nacionais impactando o ciclo de políticas e a disputa de hegemonia para governar. A legitimidade de redes de governança não está dada, precisa ser conquistada, negociada no âmbito do Estado stricto sensu e da sociedade civil. Para identificar como estas orientações políticas se difundem na América Latina e Caribe, institucionalizando-se como ação dos Estados nacionais se procura conhecer as ações do Ceppe e colaboradores que, além de elaborarem documentos e participarem das reuniões técnicas regionais com o fim de direcionar o debate sobre o tema docente, promoveram outras ações em prol da difusão das diretrizes do Projeto no Continente.

Neste estudo, foi fundamental examinar como os especialistas, vinculados às Universidades e, também, às agências multilaterais atuam na construção de consensos imprimindo suas marcas nas agendas políticas nacionais, uma vez que pensar formas de resistência aos retrocessos na Educação pressupõe conhecer como operam na disputa pela hegemonia. Ressalta-se aqui, a função crucial que os intelectuais exercem na organização da cultura, e produção da hegemonia no Estado integral que, na perspectiva gramsciana, abrange articuladamente sociedade política e sociedade civil (GRAMSCI, 1984).

Como visto, as redes promovem o intercâmbio de informações, convocam novos atores para o processo político, "validam novos discursos políticos e viabilizam novas formas de influência política" (BALL, 2008, p. 747). Nessa empreitada, o primeiro aspecto a ressaltar na estratégia de difusão das ideias do Projeto é a configuração de uma rede regional de consulta e deliberação em oito países (Argentina, Brasil, Chile, Colômbia, Guatemala, México, Peru e Trinidad e Tobago) escolhidos conforme a compatibilização entre a representatividade sub-regional e o acúmulo de experiências em políticas educativas, composto por representantes de três âmbitos: governamental, acadêmico e sindical. É difícil aos reformadores internacionais captar a distância, as barreiras institucionais e as ações de redes políticas, que se formam no interior dos países, constituindo resistências às recomendações vindas de 'outsiders' para estabelecer a agenda de políticas públicas. A resistência de segmentos nacionais e locais a essa intromissão dificultam a mera "transferência da política". A contratação de consultores nos próprios países tem sido a prática das organizações, pois em âmbito nacional, os obstáculos institucionais são mais facilmente identificáveis, bem como as barreiras nas estruturas administrativas e necessidade de flexibilizá-las para institucionalizar novas políticas.

Destaca-se, também, o apoio especializado por meio de consultorias e assessorias técnicas aos países interessados no desenho e implementação de políticas. O site do Perdalc fornece muitas notícias sobre os Seminários realizados pelo Ceppe. A análise dos informes sobre eventos evidencia o esforço de disseminação de propostas, de construção de consensos para a formulação de uma agenda comum sobre docentes na Região. A configuração das redes formadas neste projeto da Unesco remete a pensar, com ajuda das ideias de Katsikas (2010), em como as estruturas nãoestatais transnacionais afetam a política e economia nacionais e são cruciais nos processos de indigenização e legalização.

A divulgação das orientações sobre políticas docentes também é feita pela exposição das ideias-chave do Projeto pelos experts em Congressos, além disso, tais momentos são muito 
propícios para apresentação dos documentos em forma de livros que alimentam a estratégia. A Unesco também incentiva a criação de parcerias com fundações e institutos empresariais apresentados como stakeholders da Educação. Estas orientações contagiam a opinião pública por meio de reportagens, matérias em revistas, em um discurso que reproduz as interpretações sobre a "crise" educacional. O discurso não é simplesmente o conteúdo do texto, não apenas a "palavra", não se reduz a elementos ideológicos: é o conjunto do fenômeno no qual e por meio do qual a produção social dos sentidos acontece (JESSOP, 1984). Diz respeito ao compartilhamento de sentidos, à criação de um novo senso comum. A análise crítica dos discursos tem, portanto, relevância como produção cultural e de formação de agentes com subjetividades específicas, elemento crucial para a construção da hegemonia.

As ideias e valores propagados pela Unesco repercutem nas instâncias Executivas e Legislativas dos seus Estados-membros. A realização de reuniões, encontros e seminários são recorrentes, congregando ministros para ouvirem explicações dos experts sobre os imperativos de se atingir as metas educacionais e ampliar o diálogo sobre as diretrizes da estratégia regional sobre docentes, em busca de avançar na convergência de agendas e ações multilaterais. No Brasil, por exemplo, esta organização auxilia os órgãos governamentais a elaborarem e desenharem políticas públicas, enquanto na esfera Legislativa conta com o grupo de parlamentares amigos da Unesco, que praticam advocacy visando promover a discussão das propostas, bem como contribuir com a formulação de políticas públicas nacionais e aprovação de leis no campo da Educação, Ciência e Cultura. Nessa direção, muitos especialistas atuam no processo de circulação do conhecimento entre redes internacionais e locais. 
Figura 6 - Articulações de redes regionais e nacionais

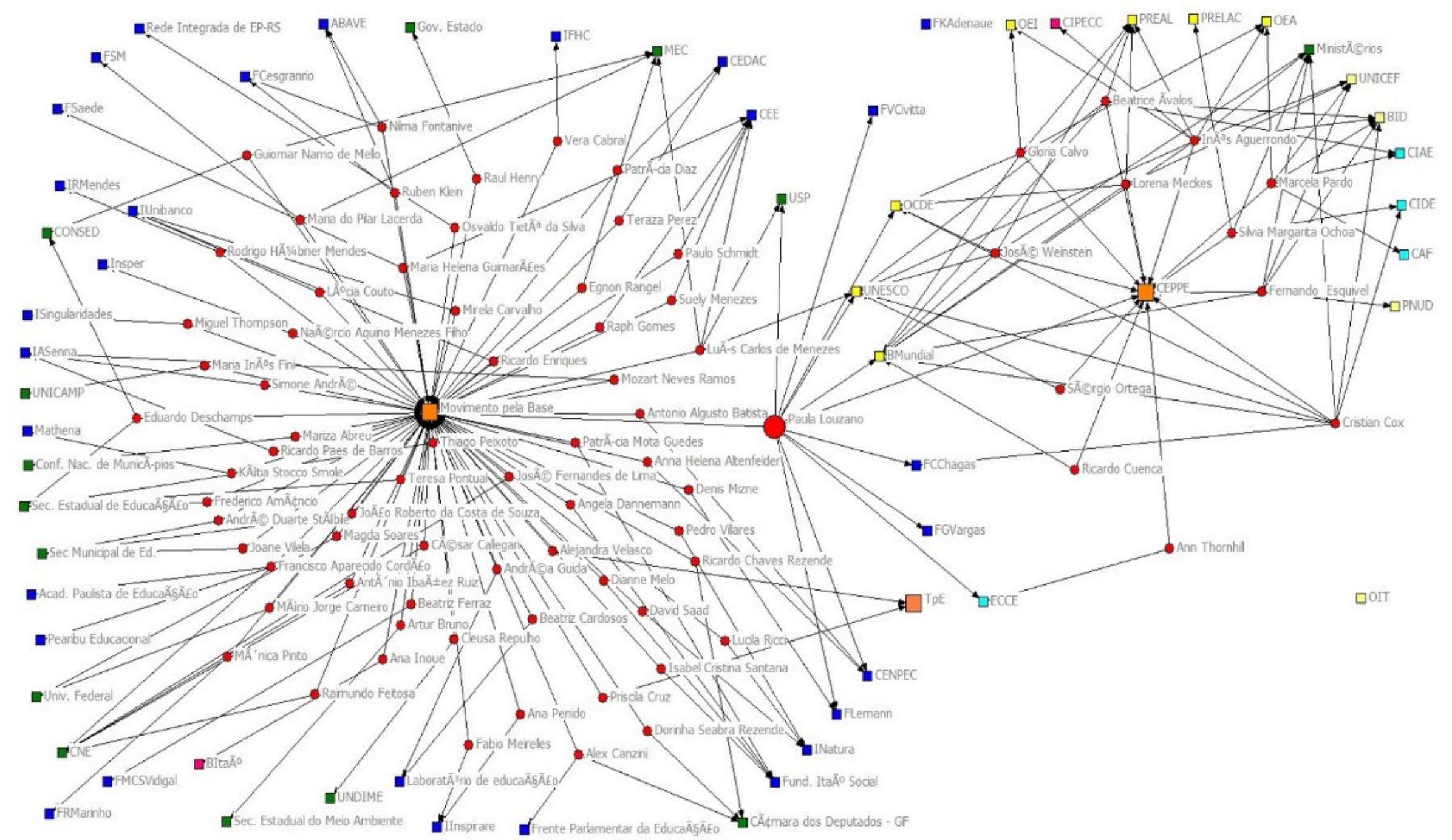

Fonte: Ceppe. Elaboração de Kátia Carvalho Lopes. 
Carvalho (2009, p.190) desenvolve a tese de que "o conhecimento educacional é socialmente construído no âmbito de redes de comunicação cujos produtos ganham materialidade no universo das publicações". Relatórios, estudos e documentos que fazem circular discursos sobre a necessidade de reformar a Educação cresceram vertiginosamente, assim como o público que acessa essas informações pelos sites, seminários e mídias sociais.

É interessante destacar que no mesmo ano em que teve início a primeira etapa do Projeto em Santiago, a Unesco patrocina um estudo sobre o mesmo tema no Brasil, intitulado "Políticas Docentes no Brasil: um estado da arte" (GATTI; BARRETO; ANDRÉ, 2011). Publicado em parceria pela UNESCO e MEC, com o apoio do Consed e Undime. Neste livro, as autoras analisam as políticas educativas relativas à formação inicial e continuada dos professores, à carreira docente, incluindo a progressão e a avaliação, as formas de ingresso e monitoramento dos professores sem experiência, como irão ingressar na escola, incentivos ao trabalho docente, destacando a "melhoria do desempenho escolar dos alunos" (Ibid, p. 11). As autoras apontam que um dos objetivos principais da obra é o de contribuir para os debates sobre as políticas docentes, subsidiando as ações que poderão contribuir para superar entraves legais que estariam "dificultando" a valorização dos professores, a melhoria da qualidade da Educação no Brasil.

Em síntese, vê-se que colaboradores do Proyecto Estratégico sobre Docentes realizam pesquisas e diagnósticos no país, participam de reuniões com Ministros de Estado, eventos patrocinados por fundações empresariais, publicações, seminários regionais com acadêmicos, gestores, Consed, Undime e representantes sindicais. Congregando estes atores, as redes de políticas públicas executam uma tarefa essencial à governança transnacional da Educação.

\section{Considerações finais}

No contexto de globalização, temas como a formação de professores, outrora questão de Estado, transcendem as fronteiras nacionais tornando-se pauta de Fóruns Mundiais como os de Incheon e de Davos. A preocupação global com o conhecimento como fator de produção mobiliza chefes de Estado, o grande capital e acionam as agências multilaterais a proporem políticas globais tomando a Educação como um dos pilares para o desenvolvimento sustentável. As redes regionais exercem um papel crucial na circulação do conhecimento produzido pelo encontro de experts, dirigentes, influenciadores e tomadores de decisões de política educacional catalisando o fluxo de informações em um duplo sentido: do local para o global e vice-versa. A repetição de ideias, de formas de apresentar os problemas e propor soluções produz uma hegemonia discursiva (FAIRCLOUGH, 2010). Reproduzida ad infinitum por diferentes segmentos sociais, as "receitas" para melhorar a Educação vão minando o senso comum, promovendo uma "recepção ativa, seletiva e interpretativa, produzindo significados no contexto de acolhimentos" (CARVALHO, 2009). Ademais, cabe observar que, nesse processo, peritos internacionais articulados com as organizações nacionais avaliam, medem, coletam indicadores nacionais, tecem comparações, diagnosticam problemas, tentam vender suas soluções e tecnologias de fazer reformas.

A literatura sobre transferência de políticas educacionais acrescida da pesquisa sobre o modus operandi das redes de experts contribuem para o estudo dos mecanismos de reprodução e de adaptação das políticas globais aos contextos locais. Os dados desta pesquisa contribuem para o entendimento de que o isomorfismo de reformas educacionais não decorre de um fenômeno espontâneo de convergência, mas de uma construção social de alinhamento de agendas internacionais e nacionais. 
A utilização da metodologia da análise de redes sociais contribui para superar a visão da política produzida por burocratas nas estruturas do aparelho de Estado, nas Câmaras e comissões do Executivo e do Legislativo que produzem normas, legislação e regulamentam a Educação brasileira. Procurou-se desenvolver uma abordagem que contemplasse os agentes, interesses políticos e econômicos, na racionalidade e no fazer política. Buscou-se evidenciar a articulação de níveis macro e micro de análise, destacando o papel das organizações multilaterais na governança transnacional promovendo, por meio das redes, a permeabilidade público-privado. Argumenta-se que experts são estratégicos nas redes que operacionalizam a internacionalização de políticas que concorrem para a desestatização da Educação pública instituindo-a como um amplo campo de atuação para o mercado financeiro, como indicam as contrarreformas no Brasil.

Estudar as redes de políticas públicas contribui para evidenciar relações entre sujeitos e organizações de mundos muito distintos, viabilizam demonstrar não só o alinhamento de propostas nacionais às internacionais, a mixagem de racionalidades de diferentes setores, estimulando o desenvolvimento de outras pesquisas que permitam conhecer não só as propostas das organizações multilaterais para Educação, nas diversas partes do globo, mas mais do que isso, desvelar seus fins, o que esses esperam obter nos diversos territórios, por meio da Educação.

\section{Referências}

ARAÚJO JÚNIOR, J. F. O trabalhador da educação e a acumulação flexível do capital: um estudo do posicionamento do Sintego frente à política educacional de Goiás. 2013. 128 f. Dissertação (Mestrado em Educação) - Universidade Federal de Goiás, Goiânia, 2013.

BALL, S. J. New philanthropy, new networks and new governance in education. Political Studies, v. 56, n. 4, p. 747-765, 2008. DOI: https://doi.org/10.1111/j.1467-9248.2008.00722.x

CARVALHO, L. M. Emergência e circulação do conhecimento psicopedagógico moderno (1880-1960). Estudos comparados Brasil-Portugal. Lisboa: Educa/ Unidade de I\&D de Ciências da Educação, 2009.

COWEN, R. Acting comparatively upon the educational world: puzzles and possibilities. Oxford Review of Education, v. 32, n. 5, p. 561-73, 2006. DOI: https://doi.org/10.1080/03054980600976155

CUNHA, T. M. O engajamento do setor privado na educação pública: redes UNESCO de políticas docentes para a Educação Infantil. Florianópolis: UFSC. TCC de Pedagogia, 2016.

DALE, R. Specifying globalization effects on national policy: a focus on the mechanisms. Journal of Education Policy, v. 14, n. 1, p. 1-17, 1999. DOI: https://doi.org/10.1080/026809399286468

DALE, R. Specifying globalization effects on national policy: a focus on the mechanisms. In: LINGARD, B.; OZGA, J. (Eds.). The Routledge Falmer Reader in Education Policy and Politics. Abingdon: Routledge, 2007. p. 48-74.

DALE, R. Specifying globalization effects on national policy: a focus on the mechanisms. Journal of Education Policy, n. 14, n. 1, p. 1-17, 1999. DOI: https://doi.org/10.1080/026809399286468 
FAIRCLOUGH, N. Critical Discourse Analysis: the critical study of language. 2 ed. Harlow: Pearson, 2010.

FAZEKAS, M.; BURNS, T. Exploring the complex interaction between governance and knowledge in education. OECD Education Working Papers, n. 67, OECD Publishing. 2012. DOI: https://doi.org/10.1787/19939019

GATTI, B.; BARRETO, E. S.; ANDRÉ, M. Políticas docentes no Brasil: um estado da arte. Brasília: Unesco/MEC, 2011.

GRAMSCI, A. Maquiavel a Política e o Estado Moderno. 5. ed. Rio de Janeiro: Civilização Brasileira, 1984.

HANNEMAN, R. A.; RIDDLE, M. Introduction to social network methods. Riverside, CA: University of California, 2005.

JESSOP, B. The capitalist state: Marxist theories and methods. Oxford: Basil Blackwell, 1984.

KATSIKAS, D. Non-state authority and global governance. In: RENGGER, N. (Ed.). Evaluating Global Orders, Review of International Studies, v. 36, n. 51, p. 113-135, 2010. DOI: https://doi.org/10.1017/S0260210510000793

KU, H. B.; YUEN-TSANG, A. W. K. Capacity building. In: BERVIR, M. (Org.). The Sage Handbook of Governance. London: Sage, 2011.

LOUZANO, P.; MORICONI, G. Visão da docência e características dos sistemas de formação docente. In: UNESCO. Temas críticos para formular nuevas políticas docentes en América Latina y el Caribe: el debate actual. Santiago, $\mathrm{Cl}$ : Centro de Estudios de Políticas y Prácticas en Educación, 2014. p. 0-52.

NEVES, L. M. W. (Org.). A nova pedagogia da hegemonia: estratégias do capital para educar o consenso. São Paulo: Xamã, 2005.

PERRY, L. B.; TOR, G. H. Educational transfer: Analytical frameworks, conceptualizations and motives. In: 35th Annual Conference of the Australian and New Zealand Comparative and International Education Society, University of Auckland, 2007.

PERRY, L. B.; TOR, G. Understanding educational transfer: theoretical perspectives and conceptual frameworks. Prospects, v. 38, n. 4, 509-526, 2008. DOI: https://doi.org/10.1007/s11125-009-9092-3

SCHWARTZMAN, S.; COX, C. (Orgs.). Políticas educacionais e coesão social: uma agenda latino-americana. Rio de Janeiro: Elsevier; São Paulo: Instituto Fernando Henrique Cardoso, 2009.

SHIROMA, E. O. et al. Redes de políticas públicas e governança da educação: pesquisando a convergência das políticas para docentes nas agendas para a próxima década. Florianópolis: UFSC, 2016. Relatório de Pesquisa. 
SHIROMA, E. O.; BRITO NETO, A. C. Em nome da qualidade: construindo estándares para o gerenciamento de professores. Movimento, Niterói, v. 2, p. 1-25, 2015. DOI: https://doi.org/10.22409/mov.v0i2.252

STEINER-KHAMSI, G.; WALDOW, F. Policy borrowing and lending in education. London: Routledge, 2012.

UNESCO. Antecedentes y Criterios para la Elaboración de Políticas Docentes en América Latina y el Caribe. Santiago, CL: Centro de Estudios de Políticas y Prácticas en Educación, 2013.

UNESCO. Catastro de experiencias relevantes de políticas docentes en América Latina y el Caribe. Santiago, CL: Centro de Estudios de Políticas y Prácticas en Educación, 2014.

Recebido em 29/09/2019

Versão corrigida recebida em 20/11/2019

Aceito em 21/11/2019

Publicado online em 05/12/2019 